\title{
The central nervous system penetration of dexketoprofen and etoricoxib
}

Piirainen A. ${ }^{1}$, Kokki M. ${ }^{1,4}$, Lehtonen M. ${ }^{2}$, Miettinen $H_{.}{ }^{3}$, Ranta V.-P. ${ }^{2}$, Kokki H. 4

${ }^{1}$ Kuopio University Hospital, Anaesthesia and Operative Services, Kuopio, Finland, ${ }^{2}$ University of Eastern Finland, School of Pharmacy, Faculty of Health Sciences, Kuopio, Finland, ${ }^{3}$ Kuopio University Hospital, Dept of Orthopaedic Surgery, Kuopio, Finland, ${ }^{4}$ University of Eastern Finland, Faculty of Health Sciences, Dept of Anaesthesiology and Intensive Care, Kuopio, Finland

Background and Goal of the Study: Non-steroidal antiinflammatory drugs are highly effective in early postoperative pain. However, in postoperative pain management the onset of analgesic action of etoricoxib is relatively slow, which could be due to delayed central nervous system penetration (1). On the contrary, dexketoprofen permeates blood brain barrier readily and its analgesic action is fast (2). To test this hypothesis, we designed the present randomised clinical trial where the primary aim was to compare the cerebrospinal fluid (CSF) penetration of dexketoprofen and etoricoxib in patients having elective primary total hip arthroplasty (THA).

Materials and methods: The study was approved by the local Research Ethics Committee and Finnish Medicines Agency was notified. After informed written consent a total of 24 patients, aged 40-75 years, scheduled for THA were enrolled. After the surgery 12 of them received a single iv-dose of dexketoprofen $0.5 \mathrm{mg} / \mathrm{kg}$, and 12 subjects $1-1.2 \mathrm{mg} / \mathrm{kg}$ of etoricoxib by mouth. A paired blood and CSF sample were taken up to $24 \mathrm{~h}$ for drug concentrations. The intensity of postoperative pain was recorded during the first 24 postoperative hours.

Results and discussion: Dexketoprofen was detected in CSF in 9/11 subjects at 30 minutes and in all subjects at 60 minutes after administration, compared to etoricoxib with $7 / 12$ subjects at 30 minutes and $8 / 12$ subjects at 60 minutes, respectively. The pharmacokinetic data of dexketoprofen and etoricoxib are presented in Table 1. Pain relief, opioid consumption and adverse events were similar in the two groups.

Conclusion: Dexketoprofen and etoricoxib entered the CSF readily, already at 30 minutes after administration dexketoprofen was detected in CSF in most subjects and etoricoxib after 60 minutes, respectively. A single dose of dexketoprofen and etoricoxib provided similar pain relief after major orthopaedic surgery.

Table 1. Pharmacokinetic data of dexketoprofen and etoricoxib

Data are median [minimum, maximum]

Dexketoprofen Etoricoxib group group

\section{Plasma}

$\mathrm{C}_{\max }(\mathrm{ng} / \mathrm{ml})$

$t_{\max }(\mathbf{h r})$

$\mathbf{T}_{1 / 2}(\mathrm{hr})$

$[1455,3292] \quad 881[314,1301]$

$2.9[1.4,5.4] \quad 19.9[7.5,39.3]$

AUC $_{0-6 \mathbf{h}}\left(\mathbf{h r}{ }^{*} \mathbf{n g} / \mathbf{m l}\right) \quad 3998[3153,5992] \quad$ Not applicable

CSF

\begin{tabular}{lcc}
\hline $\mathbf{C}_{\max }(\mathbf{n g} / \mathrm{ml})$ & $4.0[1.9,13.9]$ & $73[36,127]$ \\
$\mathbf{t}_{\max }(\mathbf{h r})$ & $3[2,5]$ & $5[1,24]$ \\
\hline $\left.\mathbf{T}^{1 / 2} \mathbf{( h r}\right)$ & $7.1[2.2,35]$ & $25[10,38]$ \\
\hline $\mathbf{A U C}_{\mathbf{0 - 6 h}}\left(\mathbf{h r}{ }^{*} \mathbf{n g} / \mathbf{m l}\right)$ & $15.8[11.2,54.5]$ & Not applicable
\end{tabular}

AUC $_{0-6 \mathrm{~h}}\left(\mathrm{hr}{ }^{*} \mathrm{ng} / \mathrm{ml}\right) \quad 15.8[11.2,54.5] \quad$ Not applicable

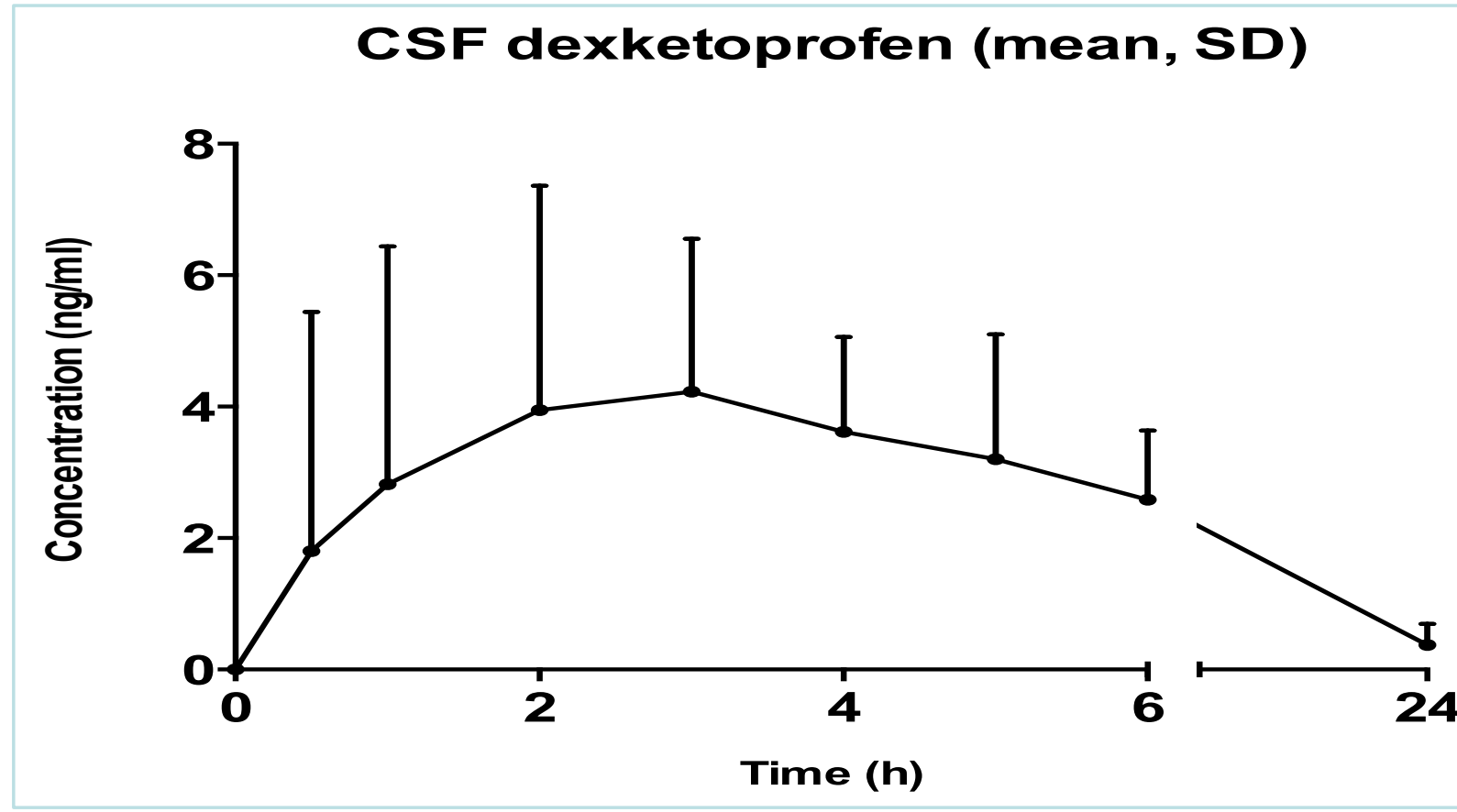

CSF etoricoxib (mean, SD)

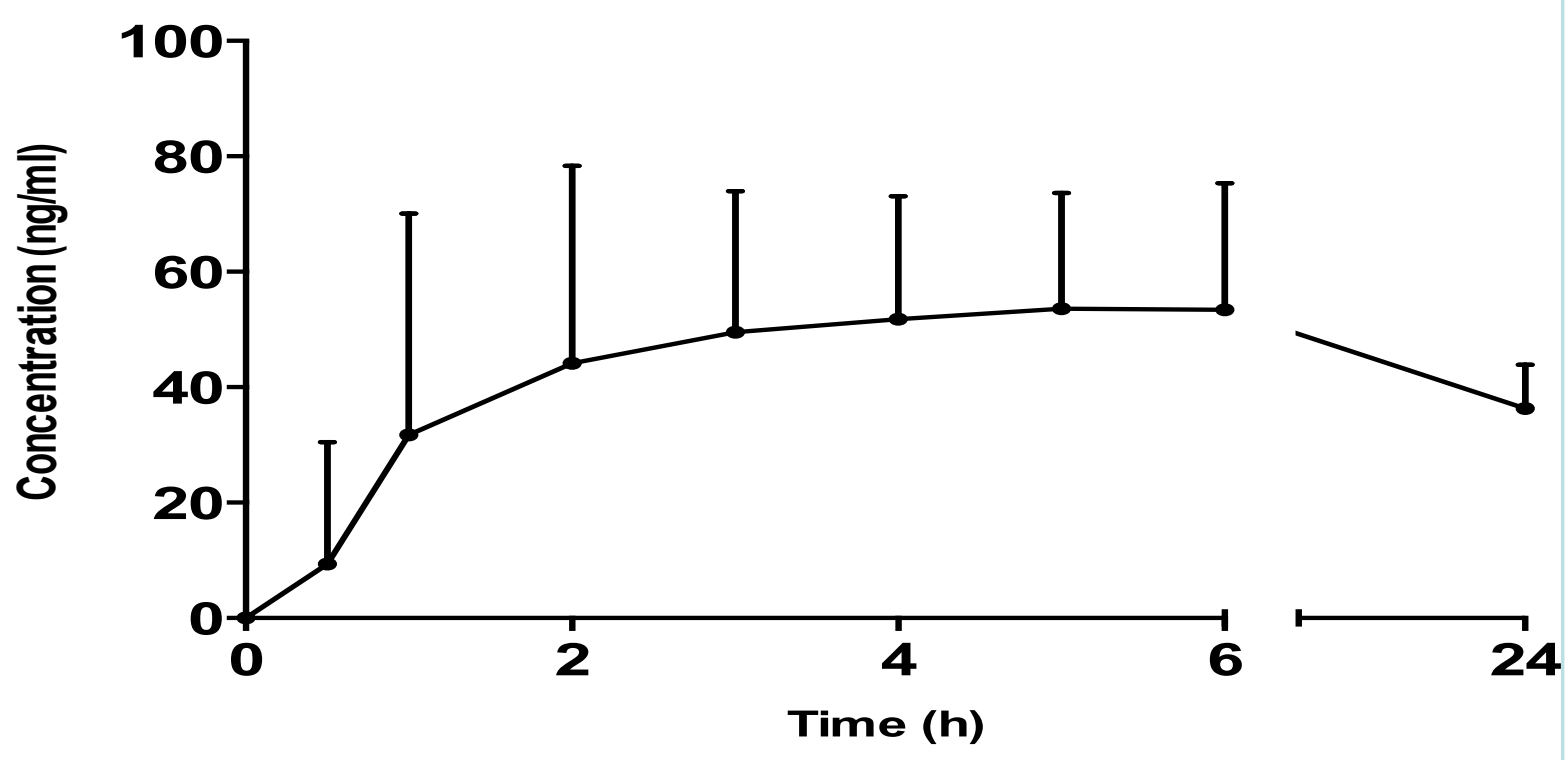

1. Smirnov G, Terävä M, Tuomilehto H, Hujala K, Seppänen M, Kokki H. Etoricoxib for pain management during thyroid surgery-a prospective, placebo-controlled study. Otolaryngol Head Neck Surg 2008;138:92-7

2. Mannila A, Kokki H, Heikkinen M, et al. Cerebrospinal fluid distribution of ketoprofen after intravenous administration in young children. Clin Pharmacokinet 2006;45:737-43 